Article

\title{
Acid-Base Catalytic Effects on Reduction of Methanol in Hot Water
}

\author{
Satoshi Inaba \\ School of International Liberal Studies, Waseda University, 1-6-1 Nishiwaseda, Shinjuku-ku, \\ Tokyo 169-8050, Japan; satoshi.inaba@waseda.jp; Tel.: +81-3-5286-1730
}

Received: 9 April 2019; Accepted: 17 April 2019; Published: 21 April 2019

check for updates

\begin{abstract}
We have performed a number of quantum chemical simulations to examine the reduction process of methanol in hot water. Methanol is converted into a methane by capturing a hydrogen molecule and leaving a water molecule behind. The required energy for the reduction is too high to proceed in the gas phase. The energy barrier for the reduction of methanol is reduced by the catalytic effect of water molecules when we consider the reduction in aqueous solution. However, the calculated reduction rate is still much slower than that found experimentally. The ion product of water tends to increase in hot water, even though it eventually decreases at the high temperature of supercritical water. It is valuable to consider the acid-base catalytic effects on the reduction of methanol in hot water. The significant reduction of the energy barrier is accomplished by the acid-base catalytic effects due to hydronium or hydroxyde. Mean collision time between a hydronium and a methanol in hot water is shorter than the reduction time, during which a methanol is converted into a methane. The calculated reduction rate with the acid-base catalytic effects agrees well with that determined by laboratory experiments. The present study reveals a crucial role of the acid-base catalytic effects on reactions in hot water.
\end{abstract}

Keywords: reaction rate; methanol; methane; acid-base; hot water

\section{Introduction}

Molecular hydrogen gas detected by Cassini spacecraft indicates water-rock interaction in active hydrothermal systems within Saturn's icy moon Enceladus [1]. Composition and temperature of the hydrothermal system in Enceladus were estimated using the composition and the size of fine silica dust particles discovered by Cassini [2,3]. The dust particles emerging from the south pole of Enceladus continuously supply the Saturn's E ring [4]. In addition, Cassini detected a number of gas species such as carbon dioxide, ammonia, and methane in the erupting plume. Methane might be produced in hydrothermal systems by methanogens [5] or by abiogenic reductive reactions of carbon dioxide.

Substantial amount of molecular hydrogen gas is observed to generate during serpentinization of ultramafic rocks in hydrothermal vents on the Earth [6,7] and in laboratories. The hydrogen molecules are involved in a sequence of reductive reactions of single carbon compounds and convert dissolved carbon dioxide into methane by mineral catalyzed hydrothermal reactions [8-10]. Isotopic labeling of dissolved carbon dioxide is used to identify the source of the produced methane in the hydrothermal conditions [11-13]. It was shown that high temperature water is required for the synthesis of methane from dissolved carbon dioxide.

High temperature water has different properties from ambient liquid water: low density and low dielectric constant [14-16]. Specially water with the temperature and the pressure above the critical point $\left(374{ }^{\circ} \mathrm{C}, 218 \mathrm{~atm}\right)$ is called supercritical water. Supercritical water is an ideal medium to destruct organic compounds and is studied extensively in science and technology. Oxidative reactions 
in supercritical water were studied using single carbon compounds such as methane, methanol, and carbon monoxide [17-19].

Brock and Savage [17] assumed that the gas phase reactions can be applied to reactions in supercritical water with the temperature range of $500-600{ }^{\circ} \mathrm{C}$. They adopted the ideal gas approximation for reactants and constructed a detailed chemical kinetics model based on combustion kinetics. The model consists of 22 species and 148 reversible elementary free-radical reactions. The numbers of elementary reactions and species can be reduced to correctly predict the concentrations because the kinetics of the oxidation is controlled by a small number of elementary reactions $[17,20]$. They successfully reproduce the experimentally determined oxidation rate of methane at the high temperature above the critical point. This indicates the validity of the ideal gas approximation to describe reactions in supercritical water. It was shown that $\mathrm{HO}_{2}$ and $\mathrm{OH}$ radials play crucial roles in the supercritical water oxidation. The calculated activation energy for the oxidation rate of methane becomes $36 \mathrm{kcal} / \mathrm{mol}$, which is smaller than the experimental value of $44 \mathrm{kcal} / \mathrm{mol}$ [19]. The predicted rate constant becomes a little higher than that determined by experimental studies when the temperature decreases to the critical temperature.

Chemical reactions in supercritical water are dominantly governed by free-radical reactions. However, free-radical reactions lose the important role in chemical reactions in hot water with the decreasing temperature [15]. Free radicals rapidly interact with other atoms or molecules and turn into a stable molecule. Instead the acid- and base-catalyzed reactions start to act effectively with an increase in the ion product. The ion product of water is dependent on the temperature and has the maximum value of $10^{-11}[\mathrm{~mol} / \mathrm{kg}]^{2}$ around $300{ }^{\circ} \mathrm{C}$ [14]. The ion product at $300{ }^{\circ} \mathrm{C}$ is nearly three orders of magnitude larger than that of ambient liquid water, suggesting a critical role of hydroniums and hydroxides in chemical reactions in hot water. Uddin et al. [21] examined the acid-base catalytic effects on the hydration of formaldehyde using the quantum mechanical/molecular mechanics-molecular dynamics. They found that hydration of formaldehyde is efficiently catalyzed by hydronium and hydroxide.

In the present study, we perform a number of quantum chemical simulations to investigate the formation of methane through the acid-base catalyzed reduction of methanol in hot water. We apply the Gaussian 4 method of the Gaussian 16 software [22] to locate and optimize the geometries of a reactant compound, a transition state, and a product compound. A reactant compound includes a hydronium or a hydroxide in addition to a methanol, a hydrogen molecule and some water molecules. We will show that the energy barrier for the reduction is significantly reduced by the acid-base catalytic effects. We calculate the acid-base catalyzed reduction rate of methanol and compare it with that determined by laboratory experiments.

\section{Computational Method}

We adopted a simple model for the reduction of methanol in hot water. A methanol interacts with a hydrogen molecule in hot water, forming a methane and a water molecule, expressed as

$$
\mathrm{CH}_{3} \mathrm{OH}+\mathrm{H}_{2} \rightarrow \mathrm{CH}_{4}+\mathrm{H}_{2} \mathrm{O} \text {. }
$$

Water molecules as well as a hydronium or a hydroxide can get involved in the reduction as catalyst. In our previous studies, we revealed the important role of water molecules during oxidative and reductive reactions of a single carbon compound [23-27]. Water molecules help to transfer a proton of a reactant molecule to proceed the reactions in aqueous solution. The energy barrier of the reaction is significantly reduced by the catalytic effect of water molecules. We included water molecules as well as a hydronium or a hydroxide in the present quantum chemical simulations to follow the motion of a proton during the reduction process.

A tentative geometry of a molecule was generated using the MOLDEN software [28]. We employ the Gaussian 16 software [22] to optimize the geometry and calculate the energy barrier for the 
reduction. The geometry was optimized using the B3LYP [29-31] functional with the 6-311+G(3df, 2p) basis set [32-35]. Then, we applied the Gaussian 4 method [36] to obtain the accurate electronic energy of the molecule. We used the MOLDEN software to display the geometries of the molecules. Figure 1 shows the calculated geometries of methane, water, methanol, hydrogen molecule, hydronium, and hydroxide with the calculated bond lengths as well as those determined by laboratory experiments. The geometries of the molecules were represented well by the calculations.
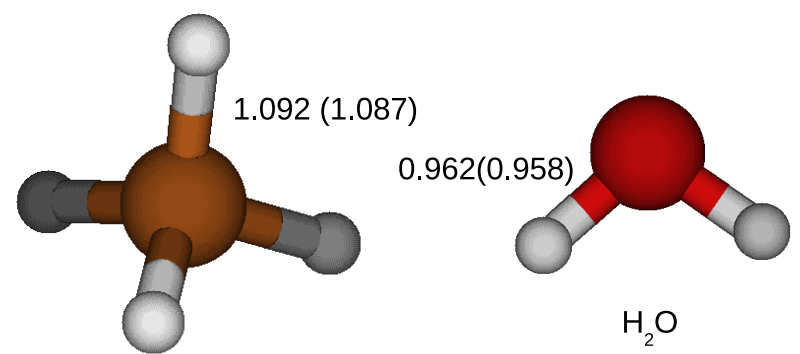

$\mathrm{CH}_{4}$

$0.742(0.741)$

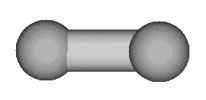

$\mathrm{H}_{2}$
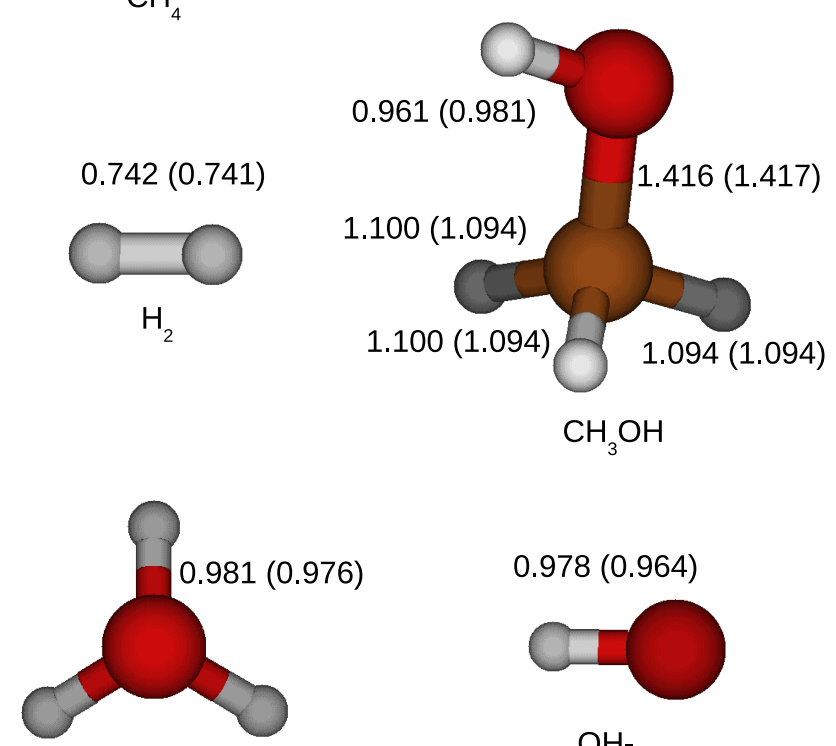

$\mathrm{H}_{3} \mathrm{O}+$

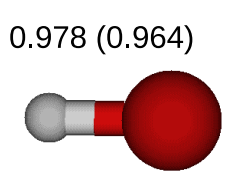

$\mathrm{OH}-$

Figure 1. Calculated geometries of molecules. Red, gray, and brown solid circles correspond to an oxygen atom, a hydrogen atom, and a carbon atom, respectively. Atoms are chemically connected with one another with a bond. The numbers next to a bond are the calculated bond length in the unit of $\AA$ with that determined by experiments [37-42] in a parenthesis.

We used a trial geometry to locate a transition state with the synchronous transit guided quasi Newton method. The transition state was confirmed by finding a single imaginary frequency of vibration. Once we obtained a transition state, we performed the intrinsic reaction coordinate (IRC) calculation and follow the minimum energy pathway to reach a reactant compound and a product compound. The reactant compound and the product compound were further optimized with the Gaussian 4 method to calculate the electronic energies and the vibrational frequencies of atoms in the compounds. We estimate the energy barrier, $\Delta E_{0}$, for the reduction of a methanol from the difference of the electronic energies corrected by the zero point energy between a reactant compound and a transition state.

We applied the transition state theory [43] to calculate the reduction rate of methanol using the following equation:

$$
k=\Gamma^{*} \frac{k_{\mathrm{B}} T}{h} \frac{q_{\ddagger}}{q_{\mathrm{rc}}} \exp \left(-\Delta E_{0} / k_{\mathrm{B}} T\right),
$$


where $\Gamma^{*}$ is the tunneling correction factor to enhance the reduction rate by the tunneling effect of a proton, $k_{\mathrm{B}}, T$, and $h$ are the Boltzmann constant, the temperature, and the Planck constant, respectively, and $q_{\mathrm{rc}}$ and $q_{\ddagger}$ are the partition functions of a reactant compound and a transition state. We approximated the potential barrier by the unsymmetrical Eckart potential and estimated the tunneling correction factor following our previous study [23]. The partition function is expressed as the product of the partition functions due to translation, rotational motion, and vibrational motion.

\section{Numerical Results and Discussion}

Our discussion begins with the reductive reaction of a methanol in the gas phase. A hydrogen molecule directly attacks a hydroxyl of a methanol in the gas phase reaction. Figure 2 shows a reactant compound, a transition state, and a product compound, calculated with the Gaussian 4 method. A hydrogen molecule is weakly bonded with a hydroxyl of a methanol by a hydrogen bond in a reactant compound. The $\mathrm{CO}$ bond of the methanol is broken when a hydrogen molecule approaches the methanol. The approaching hydrogen molecule loses one of the hydrogen atoms, which is combined with the hydroxyl of the methanol. The transition state is formed by forming a water molecule and leaving a $\mathrm{CH}_{3}$ behind. The $\mathrm{CH}_{3}$ later holds the hydrogen atom and becomes a methane. The energy barrier for the reduction is calculated from the difference of the electronic energies corrected by the zero point energy between a reactant compound and a transition state. Table 1 shows the energy barriers as well as the free energy difference between a reactant compound and a transition state. The energy barrier becomes $90.4 \mathrm{kcal} / \mathrm{mol}$ when a methanol reacts with a hydrogen molecule in the gas phase.

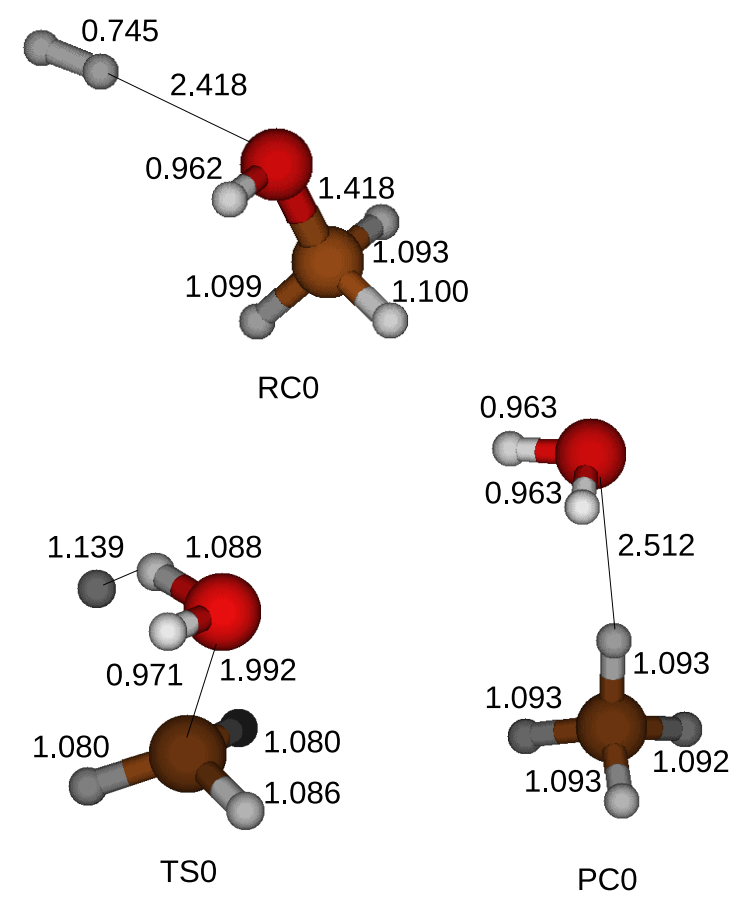

Figure 2. Calculated geometries of a reactant compound (RC0), a transition state (TS0), and a product compound (PC0) for the reduction of a methanol in the gas phase. We add thin solid lines to present the lengths between atoms in the unit of $\AA$.

A water molecule was introduced in the quantum chemical simulation to examine the effect of water molecules on the reduction of a methanol. A water molecule was weakly bonded with a hydroxyl of a methanol and a hydrogen molecule by hydrogen bonds in a reactant compound as shown in Figure 3. As in the gas phase reaction, the reduction process began with the cleavage of the $\mathrm{CO}$ bond of the methanol. A hydrogen atom of a water molecule was shared with the hydroxyl liberated from the methanol. Two water molecules appeared when a hydrogen atom was transferred 
from a hydrogen molecule in a transition state. A methane molecule arose after taking the other hydrogen atom in a product compound. The calculated energy barrier of $90.8 \mathrm{kcal} / \mathrm{mol}$ was similar to that for the gas phase reduction, indicating the ineffective catalyst of a water molecule.

Table 1. The energy barriers, $\Delta E_{0}$, as well as the free energy difference, $\Delta E_{\mathrm{G}}$, between a reactant compound and a transition state at $298.15 \mathrm{~K}$ for the reduction of a methanol in the unit of $\mathrm{kcal} / \mathrm{mol}$.

\begin{tabular}{ccc}
\hline & $\Delta \boldsymbol{E}_{\mathbf{0}}(\mathbf{k c a l} / \mathbf{m o l})$ & $\boldsymbol{\Delta} \boldsymbol{E}_{\mathrm{G}}(\mathbf{k c a l} / \mathbf{m o l})$ \\
\hline Gas Phase & 90.4 & 92.1 \\
$\mathrm{H}_{2} \mathrm{O}$ & 90.8 & 94.2 \\
$2 \mathrm{H}_{2} \mathrm{O}$ & 77.2 & 81.2 \\
$\mathrm{H}_{3} \mathrm{O}^{+}+\mathrm{H}_{2} \mathrm{O}$ & 45.4 & 46.7 \\
$\mathrm{H}_{3} \mathrm{O}^{+}+2 \mathrm{H}_{2} \mathrm{O}$ & 47.7 & 49.2 \\
$\mathrm{H}_{3} \mathrm{O}^{+}+3 \mathrm{H}_{2} \mathrm{O}$ & 49.4 & 52.4 \\
$\mathrm{H}_{3} \mathrm{O}^{+}+5 \mathrm{H}_{2} \mathrm{O}$ & 45.9 & 50.3 \\
$\mathrm{OH}^{-}+\mathrm{H}_{2} \mathrm{O}$ & 69.9 & 71.4 \\
$\mathrm{OH}^{-}+2 \mathrm{H}_{2} \mathrm{O}$ & 50.7 & 49.8 \\
$\mathrm{OH}^{-}+3 \mathrm{H}_{2} \mathrm{O}$ & 50.7 & 51.8 \\
$\mathrm{OH}^{-}+4 \mathrm{H}_{2} \mathrm{O}$ & 56.8 & 58.8 \\
\hline
\end{tabular}

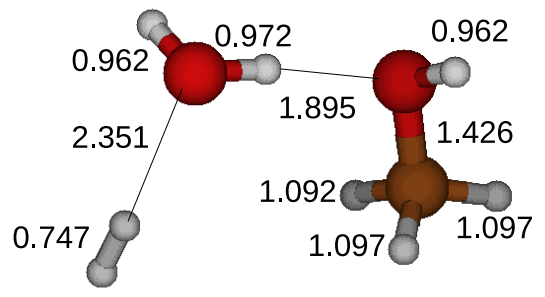

RC1

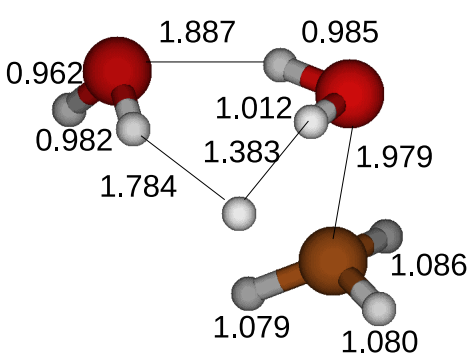

TS1

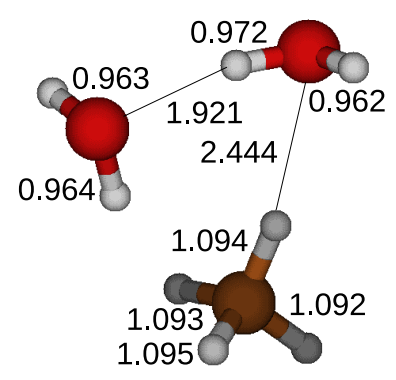

PC1

Figure 3. Calculated geometries of a reactant compound (RC1), a transition state (TS1), and a product compound (PC1) for the reduction of a methanol when a water molecule is introduced in the simulation.

One more water molecule is included in the simulation because our previous studies showed the cooperative work of water molecules to encourage the effective delivery of a hydrogen atom in a compound [23]. It was shown that the energy barrier efficiently decreases with an increase in the number of water molecules in the simulation. There were some possible locations to place a hydrogen molecules and two water molecules in the simulation. We discovered that the low energy barrier for the reduction of methanol was obtained when a hydrogen molecule approaches a carbon atom of a methanol from the opposite side with respect to the hydroxyl of the methanol as shown in the transition state of Figure 4. An approaching hydrogen molecule induced the break of the CO bond of the methanol and it being divided into two hydrogen atoms. A water molecule near a hydrogen molecule caught one of the hydrogen atoms and transport another extra hydrogen atom toward the 
other water molecule. The $\mathrm{CH}_{3}$ gained a hydrogen atom and turns into a methane. The energy barrier was reduced by $13 \mathrm{kcal} / \mathrm{mol}$, implying the catalytic role of water molecules.

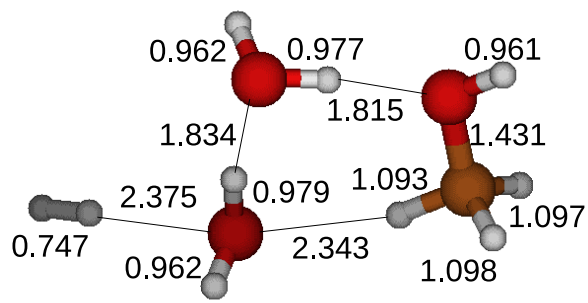

$\mathrm{RC} 2$

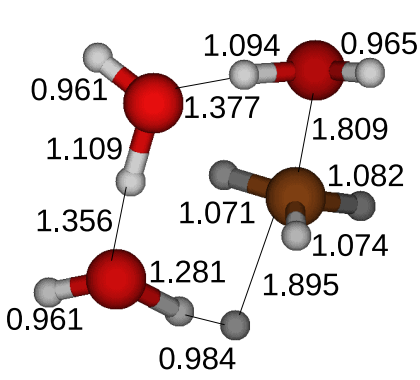

TS2

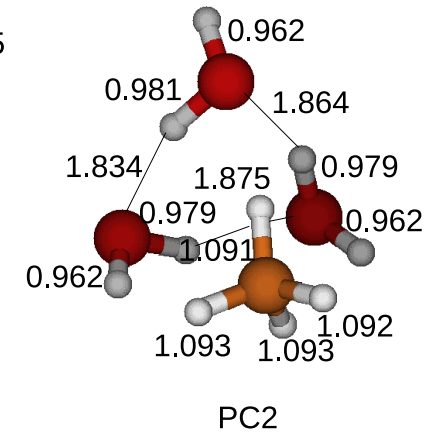

Figure 4. Calculated geometries of a reactant compound (RC2), a transition state (TS2), and a product compound (PC2) for the reduction of a methanol when two water molecules are involved in the reduction.

It would be valuable if we could compare our calculated reduction rate with that determined by experimental studies. Unfortunately we failed to find any kinetics study for the reduction of methanol by hydrogen molecule in hot water because it might take long to perform an experiment in a laboratory. We used experimental results of Seewald et al. [44] and estimated the reduction rate of methanol approximately as follows. The concentration of reactant compound decreased due to the formation of methane and the rate is represented as

$$
\frac{\mathrm{d}[\mathrm{RC}]}{\mathrm{d} t}=-k[\mathrm{RC}]
$$

where $[R C]$ is the concentration of reactant compound consisted of methanol and hydrogen molecule at time of $t$ and $k$ is a proportional constant. Since methane increased through the conversion of the reactant compound, the concentration of methane at time of $t$ is given by

$$
\left[\mathrm{CH}_{4}\right]=\left[\mathrm{CH}_{4}\right]_{0}+[\mathrm{RC}]_{0}(1-\exp (-k t)),
$$

where $\left[\mathrm{CH}_{4}\right]_{0}$ and $[\mathrm{RC}]_{0}$ are the concentrations of methane and the reactant compound at $t=0$, respectively. We determined three unknown constants: $\left[\mathrm{CH}_{4}\right]_{0},[\mathrm{RC}]_{0}$, and $k$ using the experimental data of Seewald et al., in which the concentration of methane in aqueous solution started increasing from $0 \mathrm{mmol} / \mathrm{kg}$ and becomes 0.006 and $0.012 \mathrm{mmol} / \mathrm{kg}$ at 48 and $216 \mathrm{~h}$, respectively, when the water temperature is $300{ }^{\circ} \mathrm{C}$. The concentration of methane at $t$ hours is expressed as

$$
\left[\mathrm{CH}_{4}\right]=0.012(1-\exp (-0.029 t))
$$


From this equation we obtain the experimentally determined reduction rate of methanol as

$$
k=8.0 \times 10^{-6} / \mathrm{s} .
$$

The transition state theory is applied to calculate the reduction rates of methanol in the gas phase as well as that when one or two water molecules are introduced in the simulation. The reduction rates of methanol increase with the increasing temperature. The highest reduction rate of methanol was obtained when two water molecules were involved in the reduction due to the lowest energy barrier shown in the Table 1. Figure 5 shows the calculated reduction rate as well as that given by Equation (6). The calculated reduction rate was 15 orders of magnitude lower than that determined by the experimental study.

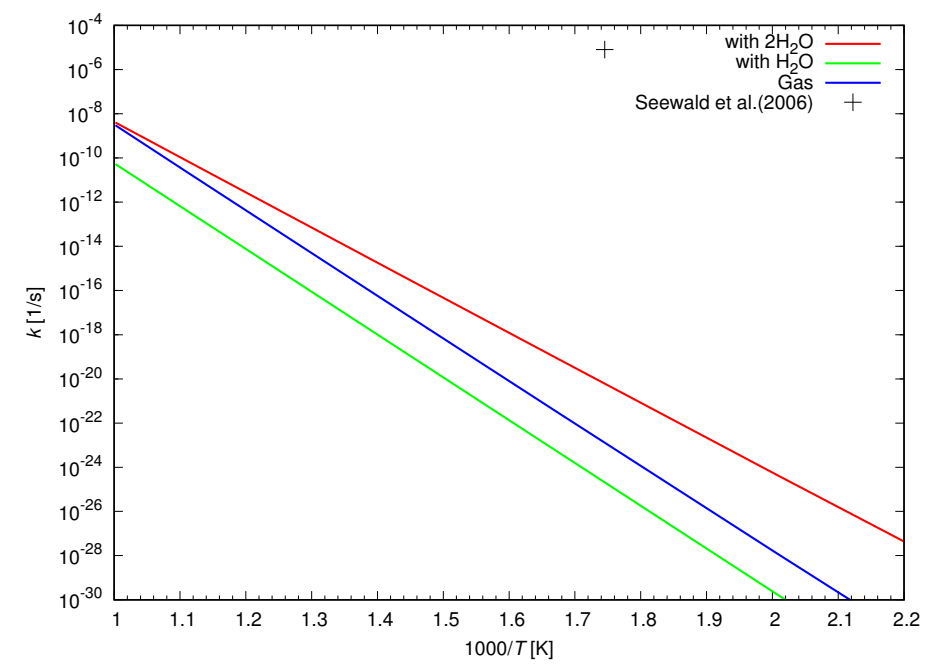

Figure 5. Rate constants for the reduction of methanol calculated in the present study as well as that determined by a laboratory experiment [44]. The rate constants were calculated when the reduction was catalyzed by up to two water molecules.

Another catalytic effect needed to be considered because the catalytic effect of water molecules was too weak to enhance the reduction rate of methanol in hot water. As noted in the introduction, the significant increase in the ion product in hot water implies a crucial role of hydronium and hydroxide as catalysts of the reduction. At first, we considered the acid-catalyzed reaction, in which a reactant compound was comprised of a methanol, a hydrogen molecule, a water molecule, and a hydronium. Figure 6 displays a reactant compound, a transition state, and a product compound when a hydronium catalyzes the reduction of a methanol. A hydronium connected with the hydroxyl of a methanol and a water molecule by hydrogen bonds in a reactant compound. The reduction process started when a hydrogen atom of a hydronium was delivered to a hydroxyl of a methanol. A hydrogen molecule and a water molecule moved toward the opposite side of the methanol with respect to the hydroxyl. A transition state was built when a water molecule was detached from the $\mathrm{CH}_{3}$. The $\mathrm{CH}_{3}$ grabbed a hydrogen atom from a hydrogen molecule and left a hydrogen atom behind. A hydronium was recovered in a product compound when a water molecule received the hydrogen atom. The lowest energy barrier of $45 \mathrm{kcal} / \mathrm{mol}$ was obtained by considering the catalytic effect of a hydronium.

We increased the number of water molecules included in the simulations as shown in Table 1. Similar energy barriers for the reduction were found. With an increase in the number of water molecules, more water molecules were required to move to new positions in a transition state. Entropy difference between a reactant compound and a transition state increases with the increasing number of water molecules. The lowest free energy difference is obtained when a single water molecule is included in the simulation. 


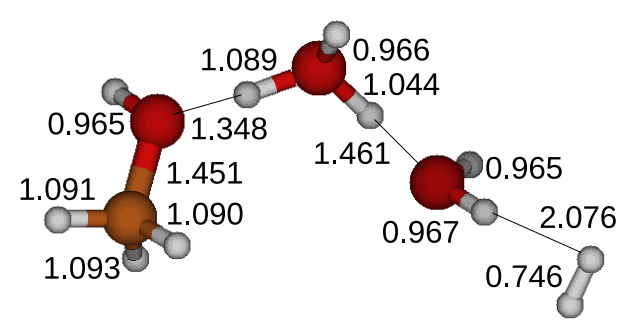

RCa1

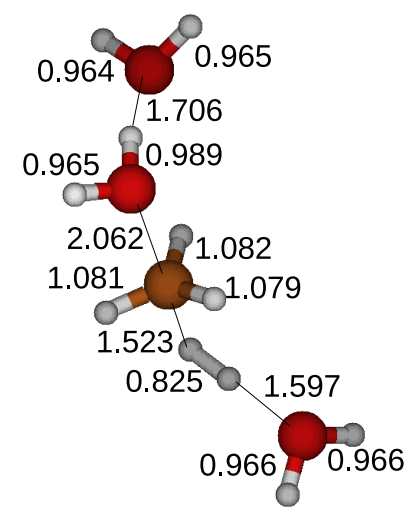

TSa1

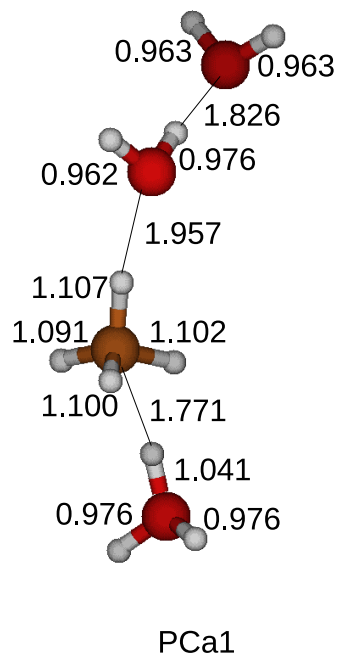

Figure 6. Calculated geometries of a reactant compound (RCa1), a transition state (TSa1), and a product compound (PCa1) for the acid catalyzed reduction of a methanol. A hydronium and a water molecule were introduced in the simulation.

Next, the base-catalyzed reduction was examined by including a hydroxyl in the simulation. Figure 7 shows that hydrogen bonds connect the hydroxyl with a methanol and a water molecule in a reactant compound. A water molecule with the label D cut the hydrogen bonds and moved toward the opposite side of the methanol with respect to the hydroxyl of the methanol. A hydroxyl of the label B took a hydrogen atom from a water molecule with the label C, which turned into a hydroxyl. A transition state appeared when a hydrogen molecule split into two hydrogen atoms and one of them was captured by the hydroxyl with the label $\mathrm{C}$. The cleavage of the $\mathrm{CO}$ bond of the methanol lead to the formation of a hydroxyl with the label $\mathrm{A}$ and $\mathrm{CH}_{3}$. The hydroxyl with the label A took a hydrogen atom from a water molecule with the label $\mathrm{B}$, while the $\mathrm{CH}_{3}$ became a methane molecule by taking an isolated hydrogen atom. A product compound was comprised of a methane, a hydroxyl, and three water molecules. It was shown that a hydroxyl acts as a catalyst in the base-catalyzed reaction. The lowest energy barrier was found when two or three water molecules are included in the simulations as displayed in Table 1 . The free energy difference became lowest when two water molecules are included in the simulation due to the smaller change of entropy during the reduction. The lowest energy barrier reduced by the catalytic effect of a hydroxyl becomes $51 \mathrm{kcal} / \mathrm{mol}$, which was a little higher than the energy barrier of the acid catalyzed reduction. 


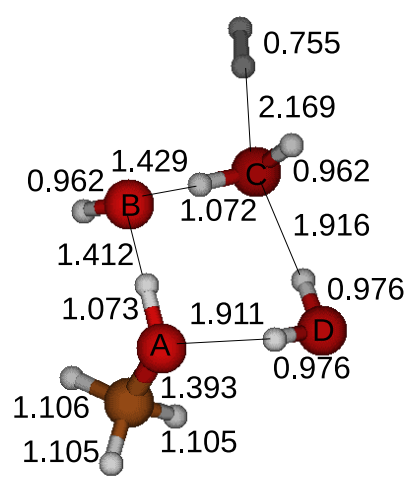

$\mathrm{RCb} 2$

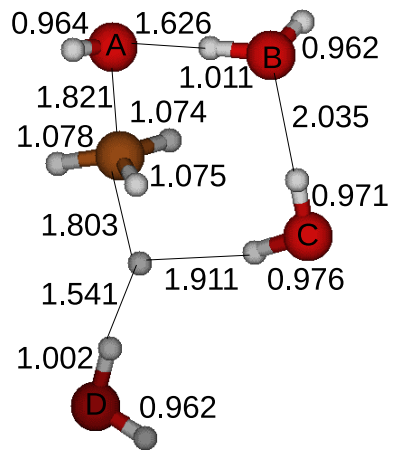

TSb2

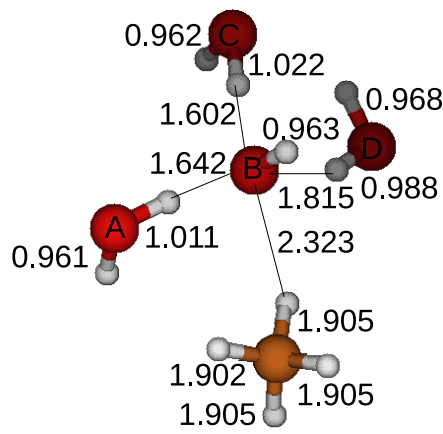

$\mathrm{PCb} 2$

Figure 7. Calculated geometries of a reactant compound ( $\mathrm{RCb} 2)$, a transition state (TSb2), and a product compound (PCb2) for the base catalyzed reduction of a methanol. Labels (A, B, C, D) were attached to oxygen atoms to distinguish between them. A hydroxide and two water molecules are introduced in the simulation.

Figure 8 presents the calculated acid-base catalyzed reduction rates of methanol. A hydronium and a water molecule are introduced in the simulation of the acid catalyzed reduction as displayed in Figure 6, while a hydroxyl and two water molecules are included in the base catalyzed reduction as shown in Figure 7. The acid catalyzed reduction rate is similar to the base catalyzed reduction rate except a little shallower slope due to the lower energy barrier. The reduction rate of methanol is significantly enhanced by the acid-base catalytic effect and becomes 15 orders of magnitude larger than that catalyzed by water molecules alone as shown in Figure 5. The acid-base catalyzed reduction rates successfully reproduce the reduction rate of methanol determined by the experimental study. This indicates the active role of a hydronium and a hydroxyl as a catalyst in the reduction of methanol in hot water.

We calculated the reduction rate of methanol, assuming that the rate was mainly determined by the reduction of a reactant compound. A reactant compound was formed after a methanol encountered a hydronium or a hydroxy in hot water. We estimated the mean collision time between a methanol and a hydronium, which, in the neutral condition, was nearly the same with the mean collision time between a methanol and a hydroxyl. The mean free path of a hydronium before encountering another methanol is given by

$$
l_{\mathrm{H}_{3} \mathrm{O}^{+}}=\frac{1}{\left[\mathrm{H}_{3} \mathrm{O}^{+}\right] \sigma},
$$

where $\left[\mathrm{H}_{3} \mathrm{O}^{+}\right]$is the number density of hydronium and $\sigma$ is the cross section for collision between a methanol and a hydronium. We estimate the cross section as $\sigma=3 \times 10^{-15} \mathrm{~cm}^{2}$ by assuming that 
a hydronium and a methanol are approximately represented by spheres with radii of $1 \AA$ and $2 \AA$. A hydronium travelled in hot water to encounter a methanol, frequently colliding with a number of water molecules. We described the motion of a hydronium in hot water as a diffusion process and estimate the mean collision time between a methanol and a hyronium as

$$
\tau_{\mathrm{H}_{3} \mathrm{O}^{+}}=\frac{l_{\mathrm{H}_{3} \mathrm{O}^{+}}^{2}}{v},
$$

where $v$ is kinematic viscosity of hot water. While a methanol interacts with a hydronium, a hydrogen molecule needs to approach to form a reactant compound. The mean collision time between a methanol and a hydrogen molecule was two orders of magnitude longer than the interaction time between a methanol and a hydronium when $\left[\mathrm{H}_{2}\right]=1 \mathrm{~mol} / \mathrm{L}$. Then the formation rate of a reactant compound was approximately estimated as

$$
k_{\text {form }}=\frac{0.01}{\tau_{\mathrm{H}_{3} \mathrm{O}^{+}}} \quad\left(\left[\mathrm{H}_{2}\right]=1 \mathrm{~mol} / \mathrm{L}\right)
$$

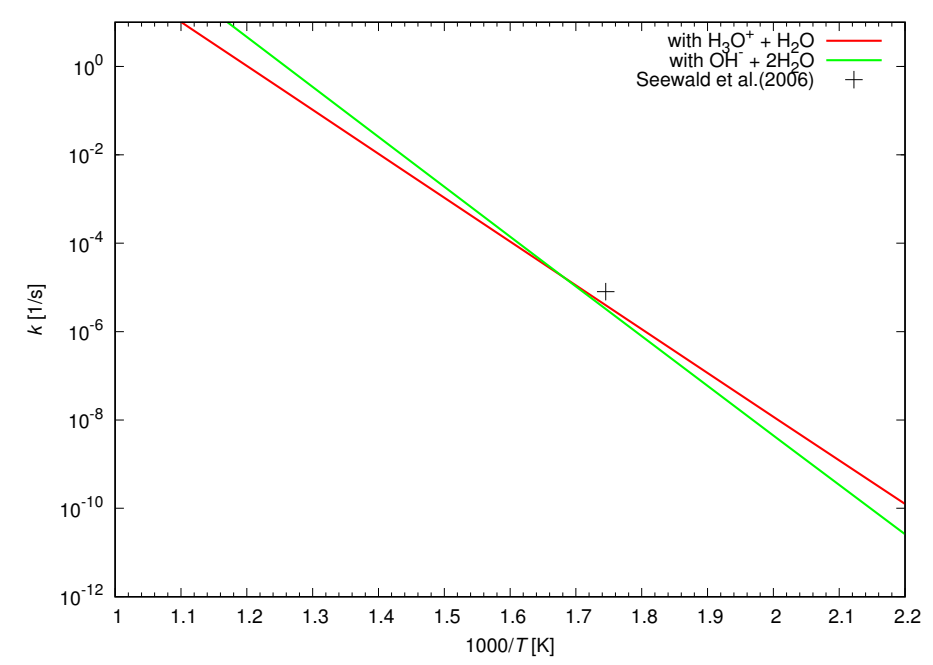

Figure 8. Rate constants for the acid-base catalyzed reductions of methanol calculated in the present study as well as that determined by the laboratory experiment [44]. A hydronium and a water molecule were included in the acid catalyzed reduction, while the reduction was catalyzed by a hydroxyl and two water molecules in the base catalyzed reduction.

The formation rate of a reactant compound depends on the water temperature because the density, the ion product, and the viscosity of water are dependent on the temperature. We adopted the data given in Akiya and Savage [14] and calculate the formation rate. Figure 9 displays the acid catalyzed reduction rate of a reactant compound as well as the formation rate of a reactant compound. The formation rate was nearly the constant value at the low temperature, while it decreased rapidly around $374{ }^{\circ} \mathrm{C}$ of the critical temperature. The reduction rate of methanol was approximately represented by the reduction rate of a reactant compound at the low temperature because a reactant compound was formed rapidly before the reduction took place. On the other hand, at the temperature above the critical temperature, we cannot obtain the reduction rate of methanol using the present method due to such slow formation rate of a reactant compound. The reduction rate was mainly determined by the formation rate of a reactant compound at the high temperature. However, in the high temperature water of supercritical water, we needed to consider free radical reactions in the reduction of methanol. 


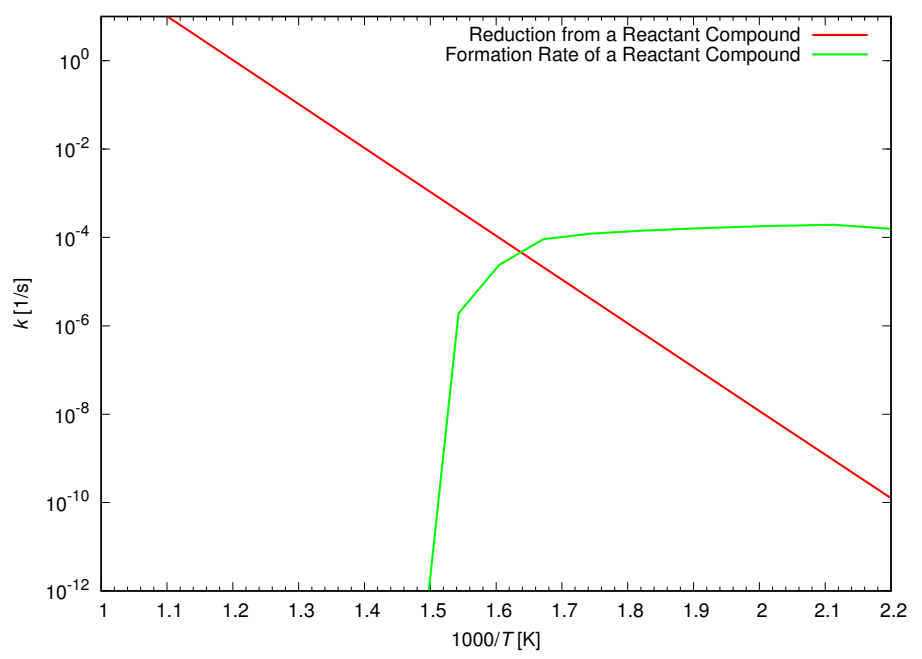

Figure 9. Rate constant for the acid catalyzed reduction of a reactant compound as well as the formation rate of a reactant compound in hot water. A hydronium approached a methanol, frequently colliding with a number of water molecules to form a reactant compound. We estimated the formation rate by representing it as a diffusion process.

\section{Conclusions}

We have performed a number of quantum chemical simulations to examine the reduction process of methanol in hot water such as hydrothermal vents. We used the Gaussian 16 software and applied the Gaussian 4 method to find optimized structures of a reactant compound, a transition state, and a product compound. A reactant compound is comprised of a methanol and a hydrogen molecule, while a methane and a water molecule form a product compound. A methanol is transformed into a methane and a water molecule by capturing a hydrogen molecule in the gas phase. Water molecules around a methanol promote the reduction process in aqueous solution by transferring a proton effectively. Two water molecules actively transfer a proton of a hydrogen molecule to a hydroxyl of the methanol to proceed the reduction. The catalytic effect of two water molecules reduces the energy barrier for the reduction by $13 \mathrm{kcal} / \mathrm{mol}$. However, the energy barrier is still too high to reproduce the reduction rate of methanol determined by laboratory experiments.

Hot temperature water exhibits very different characteristics from ambient liquid water: a low dielectric constant, fewer hydrogen bonds, and higher ion product. Broken hydrogen bonds lead to the formation of radicals and ions in hot water. Radical reactions play crucial roles in the very high temperature water such as supercritical water. With a decrease in the temperature, the contribution of ions to the reaction is expected to increase in the hot water. We examined the acid-base catalytic effects on the reduction process of methanol. Either a hydronium or a hydroxyl is included in the simulation when a acid catalyzed or a base catalyzed reduction is examined. The energy barrier for the reduction of methanol is significantly reduced when we consider the acid-base reduction of methanol. The energy barriers for the acid and base catalyzed reduction become $45 \mathrm{kcal} / \mathrm{mol}$ and $51 \mathrm{kcal} / \mathrm{mol}$, respectively.

We apply the transition state theory and calculate the reduction rate of methanol considering the tunneling effect of a proton. The reduction rate of methanol is significantly enhanced by the catalytic effect of water molecules, but it is still much lower than the reduction rate determined by an experiment. Huge drop of the energy barrier is found when a hydronium or a hydroxyl is introduced in the simulation as a catalyst of the reduction. The acid catalyzed reduction rate has a similar magnitude to the base catalyzed reduction rate. The calculated reduction rate of methanol agrees well with that determined by the experimental study. The present study suggests the active roles of hydroniums and hydroxyls as catalysts in the reduction of methanol in hot water. 
Author Contributions: S.I. performed simulations, analyzed the data, and wrote the paper.

Funding: This paper is a part of the outcome of research performed using a Waseda University Grants for Special Research Projects (Project number: 2018B-308).

Acknowledgments: Computations were performed in Research Center for Computational Science, Okazaki, Japan.

Conflicts of Interest: The authors declare no conflict of interest.

\section{References}

1. Waite, J.H.; Glein, C.R.; Perryman, R.S.; Teolis, B.D.; Magee, B.A.; Miller, G.; Grimes, J.; Perry, M.E.; Miller, K.E.; Bouquet, A.; et al. Cassini Finds Molecular Hydrogen in the Enceladus Plume: Evidence for Hydrothermal Processes. Science 2017, 356, 155-159. [CrossRef] [PubMed]

2. Hsu, H.W.; Postberg, F.; Sekine, Y.; Shibuya, T.; Kempf, S.; Horányi, M.; Juhász, A.; Altobelli, N.; Suzuki, K.; Masaki, Y.; et al. Ongoing Hydrothermal Activities within Enceladus. Nature 2015, 519, 207-210. [CrossRef] [PubMed]

3. Sekine, Y.; Shibuya, T.; Postberg, F.; Hsu, H.W.; Suzuki, K.; Masaki, Y.; Kuwatani, T.; Mori, M.; Hong, P.K.; Yoshizaki, M.; et al. High-Temperature Water-Rock Interactions and Hydrothermal Environments in the Chondrite-like Core of Enceladus. Nat. Commun. 2015, 6, 8604. [CrossRef] [PubMed]

4. Porco, C.C.; Helfenstein, P.; Thomas, P.C.; Ingersoll, A.P.; Wisdom, J.; West, R.; Neukum, G.; Denk, T.; Wagner, R.; Roatsch, T.; et al. Cassini Observes the Active South Pole of Enceladus. Science 2006, 311, 1393-1401. [CrossRef] [PubMed]

5. Taubner, R.S.; Pappenreiter, P.; Zwicker, J.; Smrzka, D.; Pruckner, C.; Kolar, P.; Bernacchi, S.; Seifert, A.H.; Krajete, A.; Bach, W.; et al. Biological Methane Production under Putative Enceladus-like Conditions. Nat. Commun. 2018, 9, 748. [CrossRef]

6. Martin, W.; Baross, J.; Kelly, D.; Russel, M.J. Hydrothermal Vents and the Origin of Life. Nat. Rev. Microbiol. 2008, 6, 805-814. [CrossRef]

7. Proskurowski, G.; Lilley, M.D.; Seeward, J.S.; Früh-Green, G.L.; Olson, E.J.; Lupton, J.E.; Sylva, S.P.; Kelley, D.S. Abiogenic Hydrocarbon Production at Lost City Hydrothermal Field. Science 2008, 319, 604-607. [CrossRef] [PubMed]

8. Berndt, M.E.; Allen, D.E.; Seyfried, W.E., Jr. Reduction of $\mathrm{CO}_{2}$ during Serpentinization of Olivine at $300{ }^{\circ} \mathrm{C}$ and 500 bar. Geology 1996, 24, 351-354. [CrossRef]

9. Horita, J.; Berndt, M.E. Abiogenic Methane Formation and Isotopic Fractionation under Hydrothermal Conditions. Science 1999, 285, 1055-1057. [CrossRef]

10. Foustoukos, D.I.; Seyfried, W.E., Jr. Hydrocarbons in Hydrothermal Vent Fluids: The Role of ChromiumBearing Catalysts. Science 2004, 304, 1002-1005. [CrossRef] [PubMed]

11. Sackett, W.M.; Chung, H.M. Experimental Confirmation of the Lack of Carbon Isotope Exchange between Methane and Carbon Dioxides at High Temperature. Geochim. Cosmochim. Acta 1979, 43, 273-276. [CrossRef]

12. McCollom, T.; Seewald, J.S. A Reassessment of the Potential for Reduction of Dissolved $\mathrm{CO}_{2}$ to Hydrocarbons during Serpentinization of Olivine. Geochim. Cosmochim. Acta 2001, 65, 3769-3778. [CrossRef]

13. McCollom, T. Abiotic Methane Formation during Experimental Serpentinization of Olivine. Proc. Natl. Acad. Sci. USA 2016, 113, 13965-13970. [CrossRef] [PubMed]

14. Akiya, N.; Savage, P.E. Roles of Water for Chemical Reactions in High-Temperature Water. Chem. Rev. 2002, 102, 2725-2750. [CrossRef] [PubMed]

15. Watanabe, M.; Sato, T.; Inomata, H.; Smith, R.L., Jr.; Arai, K.; Kruse, A.; Dinjus, E. Chemical Reactions of $\mathrm{C}_{1}$ Compounds in Near-Critical and Supercritical Water. Chem. Rev. 2004, 104, 5803-5821. [CrossRef]

16. Galkin, A.A.; Lunin, V.V. Subcritical and Supercritical Water: A Universal Medium for Chemical Reactions. Russ. Chem. Rev. 2005, 74, 21-35. [CrossRef]

17. Brock, E.E.; Savage, P.E. Detailed Chemical Kinetics Model for Supercritical Water Oxidation of $\mathrm{C}_{1}$ Compounds and $\mathrm{H}_{2}$. AIChE J. 1995, 41, 1874-1888. [CrossRef]

18. Brock, E.E.; Oshima, Y.; Savage, P.E.; Barker, J.R. Kinetics and Mechanism of Methanol Oxidation in Supercritical Water. J. Phys. Chem. 1996, 100, 15834-15842. [CrossRef]

19. Savage, P.E.; Yu, J.; Stylski, N.; Brock, E.E. Kinetics and Mechanism of Methane Oxidation in Supercritical Water. J. Supercrit. Fluids 1998, 12, 141-153. [CrossRef] 
20. Brock, E.E.; Savage, P.E.; Barker, J.R. A Reduced Mechanism for Methanol Oxidation in Supercritical Water. Chem. Eng. Sci. 1998, 53, 857-867. [CrossRef]

21. Uddin, N.; Choi, T.H.; Choi, C.H. Origin of Acid-Base Catalytic Effects on Formaldehyde Hydration. J. Phys. Chem. A 2016, 118, 9598-9606. [CrossRef] [PubMed]

22. Frisch, M.J.; Trucks, G.W.; Schlegel, H.B.; Scuseria, G.E.; Robb, M.A.; Cheeseman, J.R.; Scalmani, G.; Barone, V.; Petersson, G.A.; Nakatsuji, H.; et al. Gaussian 16, Revision A.03; Gaussian, Inc.: Wallingford, CT, USA, 2016.

23. Inaba, S. Theoretical Study of Water Cluster Catalyzed Decomposition of Formic Acid. J. Phys. Chem. A 2014, 118, 3026-3028. [CrossRef] [PubMed]

24. Inaba, S. Theoretical Study of Decomposition of Methanediol in Aqueous Solution. J. Phys. Chem. A 2015, 119, 5816-5825. [CrossRef] [PubMed]

25. Inaba, S.; Sameera, W.M.C. Dehydration of Methanediol in Aqueous Solution: An ONIOM(QM/MM) Study. J. Phys. Chem. A 2016, 119, 5816-5825. [CrossRef] [PubMed]

26. Inaba, S. Primary Formation Path of Formaldehyde in Hydrothermal Vents. Orig. Life Evolut. Biosph. 2018, 48, 1-22. [CrossRef] [PubMed]

27. Inaba, $\mathrm{S}$. Catalytic Role of $\mathrm{H}_{2} \mathrm{O}$ Molecules in Oxidation of $\mathrm{CH}_{3} \mathrm{OH}$ in Water. Catalysts 2018, 8, 157. [CrossRef]

28. Schaftenaar, G.; Noordik, J.H. Molden: A Pre- and Post-Processing Program for Molecular and Electronic Structures. J. Comput.-Aided Mol. Des. 2000, 14, 123-134. [CrossRef] [PubMed]

29. Becke, A.D. Density-Functional-Exchange-Energy Approximation with Correct Asymptotic Behavior. Phys. Rev. A Gen. Phys. 1988, 38, 3098-3100. [CrossRef]

30. Lee, C.; Yang, W.; Parr, R.G. Development of the Colle-Salvetti Correlation-Energy Formula into a Functional of the Electron Density. Phys. Rev. B Condens. Matter Mater. Phys. 1988, 37, 785-789. [CrossRef]

31. Miehlich, B.; Savin, A.; Stoll, H.; Preuss, H. Results Obtained with the Correlation Energy Density Functionals of Becke and Lee, Yang and Parr. Chem. Phys. Lett. 1989, 157, 200-206. [CrossRef]

32. Ditchfield, R.; Hehre, W.J.; Pople, J.A. Self-Consistent Molecular-Orbital Methods. IX. An Extended Gaussian-Type Basis for Molecular-Orbital Studies of Organic Molecules. J. Chem. Phys. 1971, 54, 724. [CrossRef]

33. Hehre, W.J.; Ditchfield, R.; Pople, J.A. Self-Consistent Molecular-Orbital Methods. XII. Further Extensions of Gaussian-Type Basis Sets for Uses in Molecular Orbital Studies of Organic Molecules. J. Chem. Phys. 1972, 56, 2257. [CrossRef]

34. Clark, T.; Chandrasekhar, J.; Spitznagel, G.W.; von Ragué Schleyer, P. Efficient Diffuse Function-Augmented Basis Sets for Anion Calculations. III. The 3-21+G Basis Set for First-Row Elements, Li-F. J. Comp. Chem. 1983, 4, 294-301. [CrossRef]

35. Frisch, M.J.; Pople, J.A.; Binkley, J.S. Self-Consistent Molecular Orbital Methods 25. Supplementary Functions for Gaussian Basis Sets. J. Chem. Phys. 1984, 80, 3265. [CrossRef]

36. Curtiss, L.; Redfern, P.; Raghavachari, K. Gaussian-4 Theory. J. Chem. Phys. 2007, 126, 084108. [CrossRef] [PubMed]

37. Hirota, E. Anharmonic Potential Function and Equilibrium Structure of Methane. J. Mol. Spectrosc. 1979, 77, 213-221. [CrossRef]

38. Hoy, A.R.; Bunker, P.R. A Precise Solution of the Rotation Bending Schrödinger Equation for a Triatomic Molecule with Application to the Water Molecule. J. Mol. Spectrosc. 1979, 74, 1-8. [CrossRef]

39. Florián, J.; Leszczynski, J.; Johnson, B.G.; Goodman, L. Coupled-Cluster and Density Functional Calculations of the Molecular Structure, Infrared Spectra, Raman Spectra, and Harmonic Force Constants for Methanol. Mol. Phys. 1997, 91, 439-447. [CrossRef]

40. Johnson, R.D., III. NIST Computational Chemistry Comparison and Benchmark Database; NIST Standard Reference Database: Gaithersburg, MD, USA, 2016.

41. Sears, T.J.; Bunker, P.R.; Davies, P.B.; Johnson, S.A.; Špirko, V. Diode Laser Absorption Apectroscopy of $\mathrm{D}_{3} \mathrm{O}^{+}$: Determination of the Equilibrium Structure and Potential Function of the Oxonium Ion. J. Chem. Phys. 1985, 83, 2676. [CrossRef]

42. Rosenbaum, N.H.; Owrutsky, J.C.; Tack, L.M.; Saykally, R.J. Velocity Modulation Laser Spectroscopy of Negative Ions: The Infrared Spectrum of Hydroxide $\left(\mathrm{OH}^{-}\right)$. J. Chem. Phys. 1986, 84, 5308. [CrossRef] 
43. Eyring, H. The Activated Complex in Chemical Reactions. J. Chem. Phys. 1935, 3, 107, [CrossRef]

44. Seewald, J.S.; Zolotov, M.Y.; McCollom, T. Experimental Investigation of Single Carbon Compounds under Hydrothermal Conditions. Geochim. Cosmochim. Acta 2006, 70, 446-460. [CrossRef]

(C) 2019 by the author. Licensee MDPI, Basel, Switzerland. This article is an open access article distributed under the terms and conditions of the Creative Commons Attribution (CC BY) license (http://creativecommons.org/licenses/by/4.0/). 